\title{
Establishment on Student Comprehensive Ability Evaluation Indication System of Finance Professional for Middle Vocational Undergraduate
}

\author{
Xin Li \\ College of Finance and Trade, Bohai University, Jinzhou, 121013, China \\ liexine@163.com
}

Keywords: middle vocational undergraduate; finance professional; student comprehensive ability; evaluation indication system

\begin{abstract}
Students' comprehensive ability evaluation is the important content of the realization of competence-based education goal, the social new requirements in vocational ability and university discipline development plan. In view of the traditional evaluation index professional characteristics is not obvious and poor evaluation index connotation of the status quo, combined with financial professional demand for talent ability status, connotation and principles of establishing evaluation index system on professional ability as the foundation, constructed by six primary indexes and 28 secondary indicators of recursive class structure model, and the index of each class are described. The research achievements of this paper, on the one hand, for colleges and universities to cultivate qualified secondary vocational undergraduate financial professionals provides an efficient way, on the other hand also provides the financial enterprise recruiting talents evaluation standard.
\end{abstract}

\section{Introduction}

Vocational ability is a combination of people engaged in a professional capacity, mainly includes three aspects: basic elements: one is that in order to do a specific career and must have ability, show the qualification; Second, after entering the workplace performance of professional quality; After three, began his career with career management skills. Vocational ability evaluation is based on certain professional ability standard, through certain way to quantify the evaluation objects in is engaged in the professional activities of measurement process, finally a reliable logical conclusion. Including determine competency standards, collect performance data, and according to the standard to judge the three basic link.

System refers to a certain range or similar things according to certain order and the internal contact combination into a whole. Indication system is established to predict or evaluate research premise and foundation of the research object of the abstract according to the nature and characteristics of one aspect of the identifier is decomposed into the behavior and operational structure, and the index system of the weight of each element gives corresponding in the process. Using a single or a few indicators for secondary vocational ability of undergraduate students comprehensive evaluation has certain one-sidedness and subjectivity, usually is to establish the index system. Only scientific and reasonable evaluation index system, scientific and fair assessment conclusion is possible. In this paper, based on the principle and method of system engineering, according to the theory of career development and humanistic education theory, combined with the feature of financial professional study, in theory, help to improve vocational ability evaluation system research, will help further deepen higher vocational education theory research; In practice, help to promote the pertinence and practicability of higher vocational talents training, help to improve middle vocational undergraduate financial professional students employment competitive power.

\section{Connotation on Vocational Ability}

Connotation is the feeling of a kind of abstract, hidden in the depths of things need to get exploration and mining. The connotation of vocational ability includes three aspects [1]: 
(1) Professional ability is one of the subjective conditions up to professional task, a direct impact on the efficiency of occupational activities. Vocational education is mainly for the production, construction and services such as a line of cultivating high-quality skilled personnel, requests the student has the capability of tasks related to professional activities. Professional ability is the occupational activities effect, quality and speed of decisive ability, is engaged in a professional task must have a variety of skills, including the theory of knowledge application ability, innovation ability, organization and coordination ability, etc.

(2) Professional ability is engaged in the professional activities of the unit ability to the organic combination of multiple perspectives and multiple levels. Pure professional ability could not meet the needs of modern professional post activities, vocational education is no longer an ordinary job skills training, from multi-azimuth and multidisciplinary put forward new request to the person's professional ability. From the process point of view, is mainly refers to business and technology application ability; From the perspective of labor organization, is mainly refers to various social ability; From the professional adaptability, mainly refers to the approach ability; From a personal point of view, sustainable development is mainly refers to the ability to learn.

(3) Professional ability is the specific manifestations of individual career in specific activities. Professional ability from the Angle of higher education research, unlimited expansion of application scope, could not be generalized to all different types and different levels of education field. The benchmark for higher vocational education is to produce a line service, the role is to put the manpower advantage into intelligence advantage, the intelligence advantage into productivity, and thus the basic meaning should be linked to specific occupational activities.

\section{Establishment Principle on Indicator System}

Evaluation principle is the evaluation activity must follow the principles, standards and requirements. Only clear evaluation principles, it can ensure the normalization and scientific evaluation. According to the understanding of the nature of the evaluation rule and the characteristics of the secondary vocational students, combined with the social demand for financial specialized graduation, build the evaluation index system should follow the following principles:

(1) The systemic principle. Must have certain logical relationship between the indexes, not only should from different sides reflects vocational, technical, quality and capacity factors such as the main characteristics, but also reflect the "professional - technology - quality - the ability to" the intrinsic link between. A set of indicators, each factor independent among indicators, and contact each other, constitute an organic unity. The construction of index system is hierarchy from top to bottom, from macroscopic to microcosmic layer upon layer, and form an integral evaluation system.

(2) The principle of management of occupational. Middle vocational undergraduate education is the "employment as the guide, ability as the standard" of a new type of education, Talents cultivation has distinct pertinence. Evaluation index system of occupational should meet the following requirements: at least one is that the vocational ability evaluation index to reflect industry characteristics, type of work and jobs occupational activities; The second is, the ability of professional skills of evaluation index is closely related to the jobs in the weights of indicators should be granted higher, the confirmation of index weight should be industry enterprise personnel to participate in; Three is, according to the evaluation index and evaluation can objectively and truly reflect out the ability of students to engage in the occupational activities, unit of choose and employ persons get industry recognition.

(3) Scientific principles [2]. The index system of design and the choice of evaluation must be based on principles of scientific nature, can objectively reflect the vocational, technical, quality and capacity factors such as characteristics, can objectively comprehensively reflect the true relationship between the various indicators. Each evaluation index should be typical representative, is not too much carefully make indicators too tedious, overlapping, indicators and should not be too little Jane, avoid index information missing, there is an error, not real phenomenon, simplicity and easy for data and calculation method.

(4) The developmental principles. Evaluation of the fundamental purpose is to help students 
clearing development direction, the future development foundation. Middle vocational undergraduate students with a strong shape, in the process of evaluation, needs to be a good development direction is blended in among them, not only including the career development direction, also include the development direction of the future life path. I.e. assessments to help students set goals, clear pursuit in life, at the same time, in a timely manner to evaluate information feedback to students, let the students about their development level of accurate positioning, guides the student to foster strengths and circumvent weaknesses, in the path of life gain self-confidence, harvest hope.

(5) The principle of combining qualitative analysis with quantitative analysis. Qualitative analysis is the basic premise of quantitative analysis, no qualitative quantitative is a blind, no value; Quantitative analysis of the qualitative more scientific and accurate, and to make qualitative analysis to broad and deep conclusion. Is the two complement each other, qualitative quantitative basis, is the embodiment of qualitative and quantitative combined the flexible use of best effect can be achieved.

\section{Structure on Evaluation Indication System}

Complex problem of decision making because involves more indicators, indicators, and there are complex relations between will issue involves indexes streamline, hierarchical, constructing an index system is administrative structure model, is an effective method to solve complex problems. The usual practice is to index is divided into several levels, the upper of the lower indicators reigns, the top-down hierarchical structure called the class hierarchy. Pass class hierarchy in general can be divided into the top, middle and bottom. On the basis of fully research analysis, and combined with the research achievements of predecessors [3-7], build the index system of class hierarchy model is shown in Fig. 1.

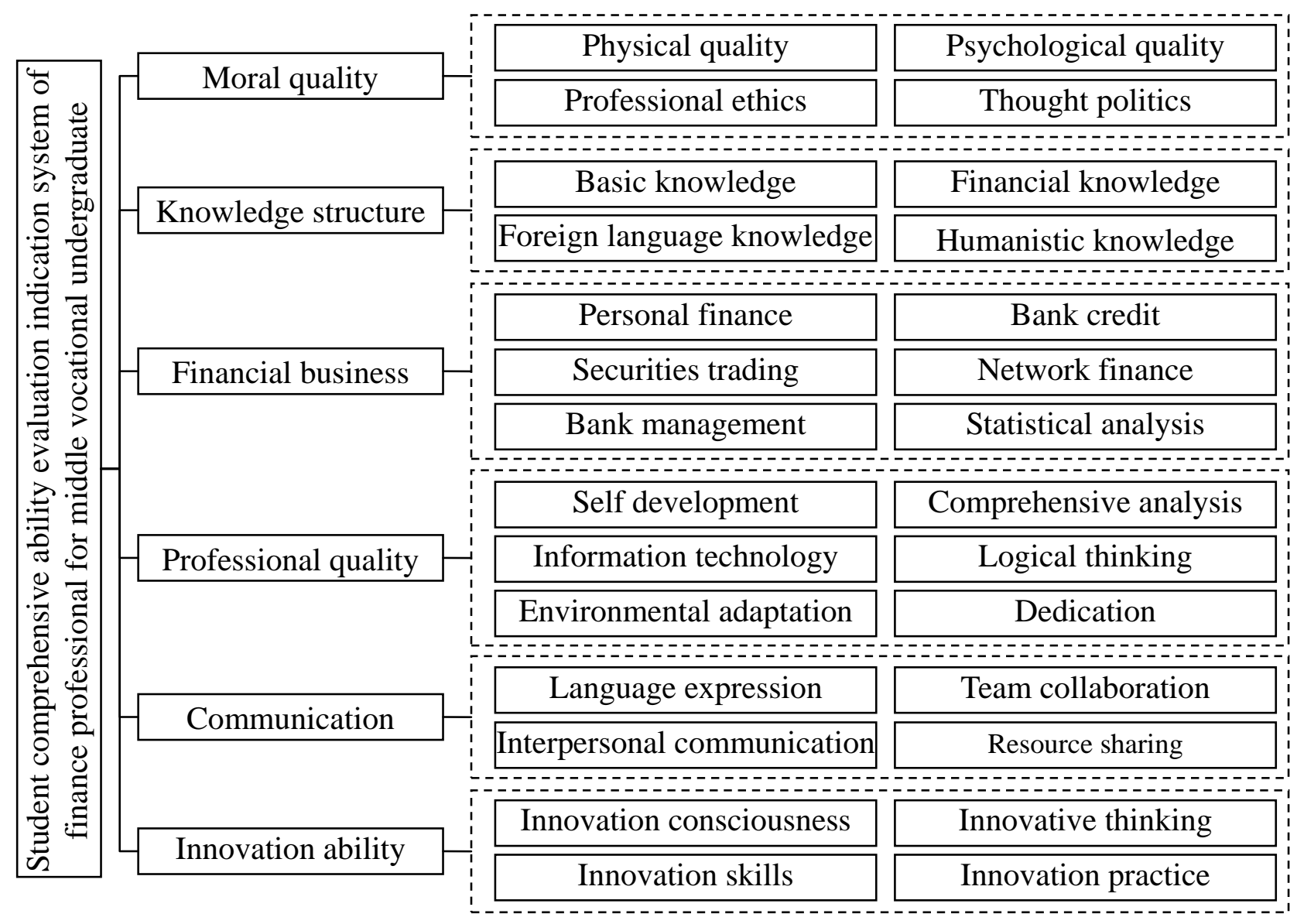

Fig.1. Hierarchical structure model on student comprehensive ability evaluation indication system of finance professional for middle vocational undergraduate 


\section{Description on Evaluation Indication}

For as shown in Fig.1 the indexes of evaluation index system are briefly described as follows:

(1) Moral quality. It is the level of people's moral cognition and moral behavior comprehensive reflection, contains a person's moral accomplishment and moral sentiment, reflect a person's level of morality and moral character. Including four secondary indexes: one is, the body quality, is one of the important symbol to measure people's physical fitness, good physical quality is the guarantee of work and study; Second, the psychological quality, refers to the person's psychology to bear ability, attaches great importance to the students psychological quality education has become a social and the request of the ages; Three, professional ethics, is closely linked with people's occupational activities required by the code of ethics, in accordance with the professional characteristics of the sum of moral sentiment and moral quality; Four is that the ideological and political, it is necessary basic conditions for people to engage in social and political activities and the basic quality.

(2) Knowledge structure. Knowledge structure refers to a person after special training have the composition of knowledge system and combining ways. Reasonable knowledge structure, that is, both profound specialized knowledge, and has a wide range of knowledge, has the development of the actual needs, the most reasonable and optimization of knowledge system. To build a reasonable knowledge structure, cultivating scientific way of thinking, improve their practical skills, so as to adapt to the future in society engaged in professional requirements. Jobs in modern society, the need is reasonable knowledge structure, according to the specific requirements in today's social development and professional to have learned all kinds of knowledge, combined scientifically, to adapt to the social requirements of talents.

(3) Financial business. The current market demand for financial talent is wider in the future of the financial industry demand for talent is diversified, financial business development needs of the multi-level financial talent. The so-called "pluralism" is to know more, want to, not just Banks, finance and insurance, including politics, economy and so on, must have the international field of vision, to adapt to the globalization, and now with the international standards of the information age. Financial talents must have profound economic, legal knowledge, a comprehensive understanding of the banking, securities, insurance, futures and other related knowledge, also called for financial talents with rich experience in financial industry, with excellent professional ethics, good interpersonal skills and organizational coordination ability.

(4) Professional quality. It is laborer professional understanding and ability to adapt to the society of a kind of integrated embodiment, is the practitioners on the basis of certain physical and mental condition, through education and training, professional practice and self-cultivation way such as the formation and development, plays a decisive role in the professional activities, internal and relatively stable basic quality. Many factors influence and restriction of professional quality, mainly including the level of education, practical experience and social environment, work experience, and some basic information. Generally speaking, laborer can smooth employment and achievements, to a great extent, depends on his own professional quality, professional quality is higher, the more you will get the chance of success.

(5) Communication. Refers to the individual in fact, emotion, value orientation and perspective aspects adopt such as the effective and appropriate method to communicate with each other and communication skill. Communication ability training mainly adopts the following method: clear communication goal, object of communication and communication situation, can the perspective-taking, improve communication consciousness; Pay attention to verbal and nonverbal communication ability training, evaluation of its communication conditions in time; Pay attention to the psychological quality of training, maintain good state of mind in communication; How to communicate with others, in practice constantly summarize the success and shortage of communication.

(6) Innovation ability. Innovation is the soul of a nation, the power for the prosperity of a country. Innovation refers to the existing mode of thinking is different from the normal or ordinary people thought idea as the guidance, the use of the existing knowledge and material, in a specific environment, in line with the idealized needs or to satisfy the needs of society, and improve or 
create new things, and can get a good effect. Innovation ability is the field of technology and practice activities to provide has economic value, social value and ecological value of new thoughts, new theory, new method and new inventions.

\section{Conclusion}

Middle vocational undergraduate finance professional training can meet the needs of the financial industry development, the comprehensive development of moral, intellectual, physical, the United States and familiar with banking, securities, insurance and trust business, with innovative spirit and sense of responsibility, have the knowledge of finance and investment aspects of basic theory and basic skills, can in banking, securities, insurance and other financial institutions and other economic management department and the enterprise engaged in the work related to cultivate specialized personnel with high quality. The research achievements of this paper, on the one hand, for colleges and universities to cultivate qualified secondary vocational undergraduate financial professionals provides an efficient way, on the other hand also provides the financial enterprise recruiting talents evaluation standard. Secondary vocational undergraduate finance majors also can self-evaluation, find out the deficiencies and strengthen learning, to increase the competitiveness to lay a solid foundation.

\section{References}

[1] R. Q. Zhou, "Construction of the evaluation index system of enterprise high skill talent," Education Teaching Forum, vol. 8, no. 7, pp. 201-202, 2016.

[2] Q. Yang, "Research on the appraisal system for evaluating of vocational higher vocational student's vocational ability," Master's degree of Zhejiang Normal University, 2010.

[3] P. Chai, "Research on evaluation studies based on comprehensive occupation ability of students in Higher Vocational Colleges," Master's degree of Guangdong Polytechnic Normal University, 2014.

[4] D. Fang, "Construction and implementation of evaluation system of Generic skills for vocational student," Master's degree of Guangdong Normal University, 2011.

[5] Y. Z. Xie, "On the construction of evaluation index system of higher vocational college students' vocational ability," Vocational Education Forum, vol. 31, no. 11, pp. 17-21, 2015.

[6] N. Ning, "Study on the Evaluation Index System of Students’ Professional Ability of Higher Vocational Colleges," Journal of Shenyang Institute of Engineering (Social Sciences), vol. 12, no. 2, pp. 262-267, 2016.

[7] F. Yang, Z. Z. Wei, "Vocational Ability and Assessment Standards for Secondary Vocational School," Journal of Lincang Teachers' College, vol. 23, no. 2, pp. 59-66, 2013. 